\title{
Movimentos sociais em redes: uma análise do Ocupa Praça em Teresina - PI
}

\author{
Social movements in networks: an analysis of Ocupa Praça in Teresina - PI
}

Jaqueline de Oliveira Sousa[a] (D), Olívia Cristina Perez[b] (D), Masilene Rocha Viana[c] (D)

\author{
[a] Universidade Federal do Piauí (UFPI), Teresina, PI, Brasil \\ [b] Universidade Federal do Piauí (UFPI), Programa de Pós-graduação em Ciência Política, Teresina, PI, Brasil \\ [c] Universidade Federal do Piauí (UFPI), Programa de Pós-graduação em Políticas Públicas, Teresina, PI, Brasil
}

Como citar: Sousa, J. O., Perez, O. C., \& Viana, M. R. (2020). Movimentos sociais em redes: uma análise do Ocupa Praça em Teresina - PI. urbe. Revista Brasileira de Gestão Urbana, 12, e20190189. https://doi.org/10.1590/21753369.012.e20190189

\section{Resumo}

Este trabalho analisa o Movimento Ocupa Praça (2015-2016), utilizando como referencial teórico a perspectiva das redes. O Ocupa Praça formou-se como resistência de moradores de um bairro de Teresina (capital do estado do Piauí) no confronto contra as investidas da Prefeitura local, que, para implementar parte do Plano de Mobilidade Urbana, pretendia suprimir uma Praça com ampla área verde. A pesquisa identificou como os distintos movimentos e organizações reforçaram o poder do Ocupa Praça na arena política. Para tanto, foram analisados documentos, informações da mídia corporativa e do Movimento em redes sociais. Também foram realizadas nove entrevistas com militantes que se configuraram como elos da rede de apoiadores e uma com representante do poder público. Como resultados, destaca-se a presença acentuada de "nós" de uma rede movimentalista que pautou a questão socioambiental no debate público e ampliou o poder de interlocução do Movimento, gerando impacto e influência sobre a política de mobilidade urbana, alterando-a conforme os interesses dos moradores.

Palavras-chave: Movimentos sociais. Movimento Ocupa Praça. Redes.

\section{Abstract}

This present work analyzes the Occupy Square Movement (2015-2016),as of the perspective of networks as a theoretical framework. Ocupa Praça was formed as a resistance group by residents of a neighborhood of Teresina (capital of the state of Piaui) in the confrontation against the attacks of the local City Hall, which, in order to implement part of the Urban Mobility Plan, intended to suppress a square with wide green area. The research identified how the different movements and organizations reinforced the power of Ocupa Praça in the political scenario. To this end, documents, information from the corporate media and the Movement on social networks were analyzed. Nine interviews were also conducted with militants who formed links in the network of supporters and one with a representative of the government. As a result, it was highlighted the strong presence of "nodes" of

JOS é bacharel em Administração, mestre em Ciência Política, e-mail: jaquelinesousa21@hotmail.com

OCP é bacharel, licenciatura plena em Ciências Sociais, doutora em Ciência Política, professora, e-mail: 889oliviaperez@gmail.com

MRV é graduada em Serviço Social, mestre em Serviço Social, doutora em Ciências Sociais, professora, membro docente permanente, e-mail: masilene@uol.com.br 
a movementist network that guided the socio-environmental issue in the public debate and expanded the Movement's power of interlocution, generating impact and influence on the urban mobility policy, changing it according to residents' interests.

Keywords: Social movements. Movement Ocupa Praça. Networks.

\section{Introdução}

Uma praça ocupada por cidadãos em defesa das árvores lá fincadas, que, em uma luta preservacionista, confrontaram as diretrizes de uma Política Pública (de mobilidade urbana) que pretendia utilizar a área para instalar um terminal de passageiros. Esse é o cenário inicial de um movimento conhecido como "Ocupa Praça", que reuniu moradores da cidade de Teresina, capital do Piauí, por vários meses entre 2015-2016, gerando impacto no planejamento dessa política, ao aglutinar organizações e movimentos sociais distintos como "nós", relevantes no processo de mobilização de forças em prol de suas demandas. As distintas ações e manifestações no espaço público punham em questão o caráter democrático do processo decisório da política de mobilidade, tencionada pelos cidadãos em defesa de uma outra ação do Estado para aquele logradouro, que focasse a questão socioambiental.

O Movimento teve suas origens em torno da preservação da Praça do bairro Parque Piauí, uma área arborizada e um dos principais espaços de lazer da comunidade. Para seus ativistas, o Plano Municipal de Mobilidade Urbana, dedicado a propor novas diretrizes de planejamento sobre o transporte público (Teresina, 2008), tinha sido construído sem participação e envolvimento efetivo dos habitantes do bairro na definição da política. Ao mesmo tempo, o movimento pautava a questão socioambiental - já que a Praça, espaço de sociabilidade e elemento gerador de conforto térmico, abrigava cerca de 200 árvores que seriam de lá retiradas. A mobilização, inicialmente circunscrita aos moradores do bairro Parque Piauí, zona sul da capital - logradouro onde se localizava a Praça -, reuniu posteriormente distintas organizações e aliados políticos, tais como Organizações Não Governamentais (ONGs), movimentos sociais, sindicatos, redes de defesa do meio ambiente, coletivos, partidos políticos, entidades de assistência jurídica, além de estudantes universitários. Em 4 de outubro de 2015, a área foi ocupada pelos manifestantes que lá permaneceram por nove meses, em ação direta e de confronto, tendo, também, utilizado estratégias de luta política institucionalizada ao longo do processo, materializada pela busca de canais e instituições de pressão, como o Ministério Público.

No outro polo desta relação, o Estado, de início, não reconheceu o Ocupa Praça como um ente legítimo para construir soluções e alternativas viáveis para o problema, por classificá-lo como um movimento que aspirava promoção política. $O$ sentido negativo atribuído a essa dimensão e a falta de reconhecimento pelo poder Estatal, de fato, resultou em tensões. 0 conflito que se explicitava na forma direta da ocupação da praça ganhou o terreno dos canais institucionais para mediações, tais como o Ministério Público Estadual (MPE-PI), e audiências públicas articuladas por vereadores. Inclusive foram apresentadas três propostas pela prefeitura em audiência mediada pelo Ministério Público do Estado (MPE-PI), em 2015, com a participação de representantes do Movimento e da associação de moradores do bairro: a primeira previa a compensação de 1.020 mudas na região do bairro; a segunda consistia na distribuição de 1000 mudas frutíferas para os moradores do bairro; a terceira proposta seria a criação do Parque Vale dos Serrados, na zona sul de Teresina (2015).

O Movimento teve êxito e o terminal de ônibus não foi construído no local inicialmente planejado, sendo instalado em outra área do bairro. 0 presente artigo, fruto de pesquisa acerca desse movimento, dirige sua atenção para a perspectiva teórica de redes, buscando, à luz dos contornos organizativos da luta, dialogar com a literatura especializada, ao tempo em que analisa também a gênese, as demandas, os elos da rede e o legado político do movimento. Assim, o trabalho se insere no campo de discussões sobre a importância da sociedade civil organizada nas decisões públicas.

Os estudos sobre movimentos sociais e sociedade civil transformaram-se ao longo do tempo. Durante a ditadura cívico-militar (1964-1985) e logo após seu fim, o foco das pesquisas estava na potencialidade dos movimentos operários e urbanos. Apostava-se neles para o estabelecimento de relações sociais mais 
horizontais e para a conquista de direitos, incluindo a ampliação dos mecanismos de participação política (Sader, 1988). Tais estudos retomavam teorias que destacavam a formação de identidades e transformações culturais promovidas pelos - na época - novos movimentos sociais europeus (cf. Melucci, 1989; Touraine, 1989). No entanto, havia quem, como Cardoso (1987), atribuísse a essa literatura um foco excessivo na existência e necessidade de autonomia dos movimentos sociais diante do Estado, indicando a necessidade de investigar a interação entre movimentos sociais e instituições estatais.

A Constituição de 1988 (CF/88) marca a volta do país à democracia e inaugura uma outra forma de relação da sociedade civil com o Estado (Brasil, 1988). Para dar conta das inúmeras organizações que proliferaram, o termo sociedade civil foi largamente utilizado como referência a organizações políticas que não pertenciam ao Estado, embora se relacionassem com ele ${ }^{1}$.

No final do século XX, surgiram novos constructos interlocutórios entre Estado, sociedade civil e movimentos sociais, em um movimento de abertura de determinadas esferas do Estado à participação e à deliberação pública (Avritzer \& Costa 2004). Exemplos desses arranjos são: conselhos gestores, fóruns, conferências e orçamentos participativos - todas elas chamadas de Instituições de Participação. Teresina, seguindo de forma particular essa inclinação de muitos governos municipais, implementou por alguns anos o que intitulou de "Orçamento Popular", a partir de 1997.

Naquela conjuntura, a participação da sociedade civil nas decisões públicas - em especial de movimentos sociais -, intensificou-se durante a gestão do Partido dos Trabalhadores (PT) no governo federal (de 2003 a meados de 2016), particularmente em face das chamadas Instituições de Participação (Labra \& Figueiredo, 2002; Tatagiba, 2002; Santos et al., 2004; Gohn, 2011). O governo do PT também promoveu a aproximação entre movimentos sociais e Estado com a escolha de lideranças de movimentos para cargos centrais na burocracia federal, fenômeno nomeado como ativismo estatal (Pires \& Vaz, 2014), com suas variações como o ativismo institucional (Cayres, 2017) ou ainda o feminismo estatal (Matos \& Paradis, 2014), quando feministas passam a formular políticas públicas. Os trabalhos sobre o tema enfocam a influência mútua existente entre poder social e o Estado, sendo um esforço pertinente para mostrar o alcance, limites e ganhos advindos desta inter-relação, portanto, partem do pressuposto de que o estudo sobre movimentos sociais deve estar associado às instituições Estatais (Abers \& Von Bülow, 2011; Dowbor, 2012; Abers et al., 2014; Pires \& Vaz, 2014; Lavalle \& Szwako, 2015; Lavalle et al., 2019; Cayres, 2017). É comum na produção sobre interações socioestatais a utilização de aportes teóricos como o da teoria do processo político (Tarrow, 2009; Tilly, 2010) que entende em linhas gerais que as estruturas de oportunidades políticas têm relação com o surgimento e estratégias dos movimentos sociais ${ }^{2}$.

0 presente trabalho se insere nesse campo de estudos, mas se diferencia dele por adotar a teoria das redes na análise de um movimento social. Conforme Diani \& Bison (2010), as redes seriam formas de interações informais travadas entre uma pluralidade de indivíduos, de grupos ou de associações. A presença de redes é central inclusive na definição de um movimento social, conforme um dos expoentes da teoria, o italiano Mario Diani. $O$ autor entende os movimentos sociais como "[...] redes de interações informais entre uma pluralidade de indivíduos, grupos ou associações, engajados em um conflito político ou cultural, com base em uma identidade coletiva compartilhada" (Diani, 1992, p. 13).

A análise das redes fornece uma perspectiva instrumental e analítica imprescindível para a decodificação de processos "interorganizacionais e interativos" (Scherer-Warren, 2005a) entre movimentos sociais e Estado na seara da produção de políticas. Destaca-se que a perspectiva das Redes tem sido um terreno fértil nas últimas décadas na análise dos movimentos sociais, uma vez que conecta diferentes dimensões da ação coletiva que antes eram vistas de maneira atomizada na análise social, portanto, sendo um modelo que vincula aportes analíticos distintos, porém complementares na explicação da ação (Diani, 2003; Scherer-Warren, 2011).

Mas essa não é uma abordagem inédita: apesar de não ser a mais comum no Brasil, trata-se do foco de análise dos trabalhos, alguns não tão recentes, de Ilse Scherer-Warren $(1998,2003,2005 a, 2005 b, 2006$,

\footnotetext{
${ }^{1}$ Um balanço das interpretações da época sobre a sociedade civil foi realizado por Lavalle (2003)

${ }^{2}$ Um balanço dessa literatura foi realizado por Perez \& Santos (2019).
} 
2007, 2008, 2011, 2013). Para a autora, os próprios movimentos sociais são redes de organizações, tendo como exemplos as grandes marchas pelo mundo "Antiglobalização" ou pela Paz (Scherer-Warren, 2005b), lutas que envolvem direitos, como a Marcha Mundial das Mulheres (MMM) (Scherer-Warren, 2006) ou o Fórum Social Mundial (Scherer-Warren, 2006, 2007). A análise de redes foi também sugerida por Abers \& Von Bülow (2011) para a compreensão das relações entre Estado e movimentos sociais, ao tempo em que as autoras apontam a insuficiência das teorias do confronto político, pois nem todos os movimentos sociais têm relações de confronto com o Estado, bem como necessidade de análise das várias relações estabelecidas entre atores sociais.

O que diferencia o trabalho atual dos anteriores é a análise das várias relações de um movimento social que ajuda a compreender a gênese, as estratégias e o êxito deles. Assim, a análise não fica circunscrita a relações com o Estado, mas envolve outros atores políticos e sociais. Ademais, considerou-se como fundamental a inclusão do espaço e do território na análise social, assim como enfatiza Ribeiro (2009). Conforme a autora, voltar-se para a realidade operante nos microespaços urbanos constitui uma orientação teórica que deve ser assumida, uma vez que conduz ao reconhecimento de formas de organização latentes, das forças que despontam na cena pública para pontuarem a relação de trocas sociais, culturais e políticas, tecedoras de narrativas de aprendizado diferenciadoras. É nessa frente de análise que surge a necessidade de se focalizar a construção de novas alternativas de engajamento, novos repertórios, novas produções sociais, novas reivindicações, a partir de uma visão crítica à política dominante, capitaneada, por sua vez, por comunidades periféricas (Ribeiro, 2009).

Logo, o trabalho se insere nessa seara de estudos, destacando a dimensão local e analisando a interação entre movimento social, Estado e outras organizações, ainda que fora das Instituições de Participação ou da burocracia oficial. 0 objetivo da pesquisa consistiu em verificar como distintos movimentos, atores e organizações reforçaram o poder do Movimento Ocupa Praça na arena política a ponto de intervir no direcionamento da política pública. Uma indagação que guiou a pesquisa foi: Como as redes de organizações potencializaram as estratégias e contribuíram para o êxito do movimento? A hipótese central, com base na teoria das redes, era de que os movimentos e organizações sociais aumentaram as chances de acesso ao sistema político, tanto por meio de canais ad hoc, como por meio de aliança com instituições com poder de pressão institucional abertas a esses atores (Della Porta \& Diani, 2006).

No que tange à metodologia, a pesquisa foi desenvolvida a partir de abordagem qualitativa, configurada como um estudo de caso que analisou repertórios e ganhos do movimento Ocupa Praça, com foco nas suas redes e como elas auxiliaram o Movimento na conquista de seus objetivos. Em momento inicial, foram levantados dados por meio das redes sociais do Movimento e registros bibliográficos sobre o Movimento, visando explorar a formação das conexões entre os elos da rede e identificar os ativistas e seus apoiadores (movimentos sociais, entidades de assessoria jurídica, etc.). Foram utilizadas como fontes informações da mídia corporativa, de redes sociais e documentos do próprio Movimento e da prefeitura, tais como ofícios e o processo de ação popular proposto pelos moradores.

Num segundo momento, foram identificados os atores do Ocupa Praça. Com base nessa identificação, foram escolhidos e entrevistados nove militantes do Movimento e um representante do poder público entre os meses de janeiro e abril de 2018. Na definição da amostra dos militantes, os critérios de escolha foram as posições de representação e de centralidade dentro do Movimento. Foram entrevistados seis mulheres e três homens; duas advogadas, uma atuante na área de direitos humanos, sindical e trabalhista (advogada 1) e a outra com experiência na área de assessoria jurídica popular na área de direitos humanos; uma ambientalista, presidente de uma ONG de defesa ambiental em Teresina e três professoras, uma delas, militante partidária; dentre os homens, foram entrevistados um engenheiro florestal, que trabalha numa ONG de defesa ambiental, um arquiteto urbanista, que presta assessoria popular na área de movimentos sociais urbanos e um militante partidário. A pesquisa contemplou também a perspectiva estatal, ao analisar documentos públicos e as argumentações e posicionamentos dos gestores públicos, além das contrapropostas apresentadas pela prefeitura de negociar com os demandantes alternativas visando viabilizar o projeto inicial. 
Em relação à organização do artigo, na primeira seção, precisamos as bases conceituais em que situamos a análise do Ocupa Praça, discorrendo acerca do potencial analítico das Redes. Na seção seguinte, abordamos o Ocupa Praça, buscando situar sua gênese, as principais demandas, os elos da rede, as alianças e o legado político deixado à cidade em prol da democratização das políticas urbanas e, em particular, por ter trazido à baila a questão ambiental na pauta dos problemas a enfrentar.

\section{O potencial analítico da perspectiva de Redes para análise de movimentos sociais}

Movimentos sociais têm sido definidos de diversas formas e por diferentes matizes de interpretação (Diani, 2003). As múltiplas trajetórias de teorização sobre movimentos sociais revelam que, tendo o conceito se desenvolvido ao longo do tempo, pensar em uma definição conceitual linear apresenta-se como um problema sensível e controverso (Alonso, 2009; Gohn, 2000, 2010), assim como em outras áreas. A própria ideia de movimentos sociais, como categoria analítica, metamorfoseia-se (Doimo, 1995), tendo, desde seu nascedouro, por volta do séc. XIX, experimentado transmutações significativas, vindo a nuclear, em tempos mais recentes, formas distintas de ação coletiva de confronto. É assim que se forjam distintas abordagens conceituais e teorias explicativas expressas na literatura da área ${ }^{3}$; não raras vezes buscando acompanhar a novidade dos atores que se insurgem com seus reclamos em conjunturas específicas.

A teoria das redes aqui adotada assevera que "[...] a ideia de rede de movimento social é um conceito de referência que busca apreender o porvir ou o rumo das ações de movimento, transcendendo as experiências empíricas, concretas, datadas, localizadas dos sujeitos/atores coletivos" (Scherer-Warren, 2006, p. 113).

A teoria das redes surgiu a partir da década de 1990, como uma literatura centrada nessa visão polifacetada, ganhando projeção ao tentar compreender a ação coletiva pela análise de campos heterogêneos dinâmicos, que antes permaneciam isolados e discursivamente concentrados em si mesmos (Toni, 2001; Alonso, 2009), assumindo, portanto, uma perspectiva de comunicação aberta por meio da qual se intercruzam dimensões complementares de análise da realidade.

É válido ponderar que os movimentos sociais sempre pautaram sua atuação em forma de redes. Ao longo de toda a história, elas têm sido usadas em larga escala na ação desses movimentos - desde os da classe trabalhadora do século XIX, passando pelos ambientais e pelos feministas (Della Porta \& Diani, 2006), assim como em outros campos de atividade humana (Castells, 2001, 2005, 2013). Contudo, tais redes se localizavam em um plano imerso ou velado na análise da ação coletiva.

Outro ponto relevante sobre a arquitetura em redes diz respeito ao seu potencial para mobilização (Della Porta \& Diani, 2006). Elas incentivam a ação, em termos mais claros, unem pessoas que já se identificam e estão envolvidas em uma determinada demanda. Por meio dessa ligação, os atores se percebem envolvidos em um projeto unificado e exequível dentro de uma causa relevante que implica um desempenho coletivo sinérgico, possibilitado por meio de um empreendimento mais arquitetônico. A ideia de Movimento social, nesse caso, reflete como um processo distinto, assegurado por intermédio de mecanismos nos quais os agentes envolvidos em conflitos com oponentes manifestadamente reconhecidos estão ligados por redes informais e compartilham uma identidade coletiva singular, o que reforça a importância desse tipo de conexão para a criação de oportunidades de participação.

Partindo de observações da realidade empírica, o movimento social passa a existir da "[...] ação intercruzada e cumulativa" (Scherer-Warren, 2003, p. 30) de diversas formas de interação e práticas na luta pela cidadania. Nessa perspectiva, apreende-se um movimento social como "[...] uma rede que conecta sujeitos e organizações de movimentos, expressões de diversidades culturais e de identidades abertas, em permanente constituição, que buscam reconhecimento na sociedade civil” (Scherer-Warren,

\footnotetext{
3 Eximimo-nos de resgatar seus aspectos essenciais aqui, seja porque já existem trabalhos relevantes sobre a questão, seja por priorizarmos alguns conceitos no diálogo com algumas dessas perspectivas e seus autores, particularmente, a teoria do processo político, a teoria dos novos movimentos sociais e os aportes teóricos da análise de movimentos em rede.
} 
2003, p. 30), o que sinaliza que, nesse processo, a organização de tais grupos começa a partir da composição dos elos de redes que se formam por meio de articulações entre sujeitos e organizações que ultrapassam barreiras territoriais e uma perspectiva localizada de manifestação e atuação.

Diani $(1992,2003)$ acata a ideia de síntese teórica no estudo das redes de movimentos sociais, embora essa noção de sincretismo teórico seja passível de problematizações. 0 que parece mais apropriado afirmar é que o estudo pelo aporte das redes constitui uma linha analítica que se orienta pela exploração de pilares explicativos de divergentes correntes teóricas, não se tratando em si de um sintetismo ou hibridismo teórico, mas de um desenvolvimento teórico-metodológico que se distingue pela capacidade de jogar luz sobre diversos enfoques, sem preteri-los.

O que a expansão do estudo de redes de movimentos sociais demonstra é que já não é suficiente reconhecer a relação existente entre redes e ação coletiva; antes, é preciso problematizar seu alcance teórico (Diani, 2003). A intenção deste trabalho é justamente aferir o potencial das redes para pensar o Movimento Ocupa Praça.

\section{Ocupa Praça: gênese, demandas, elos da rede e legado político}

A cidade de Teresina, lugar onde ocorreram as movimentações em torno do Ocupa Praça, tem uma história de urbanização acelerada a partir dos anos 1950, com ênfase na política nacional desenvolvimentista no Brasil, em que a tônica do planejamento governamental brasileiro passou a ser orientada para a industrialização, acompanhando o processo mais geral de migração campo-cidade. No entanto, a capital do Estado do Piauí nunca foi exemplo notável de desenvolvimento industrial, embora as marcas da migração do campo se façam presentes de forma significativa, sobretudo nos últimos cinquenta anos, espraiando-se no espaço urbano de diferentes formas e dando o contorno do processo de segregação que acompanha, de forma particular, a origem do bairro Parque Piauí.

O bairro Parque Piauí tem suas origens no final da década de 1960, como parte da política habitacional que, via Banco Nacional da Habitação, construía moradias nas cidades brasileiras, visando contemplar parte do contingente de novos moradores que migravam para as cidades. A criação do bairro, durante o Governo Militar, dá-se em contexto de forte incentivo estatal à expansão urbana nos planos federal, estadual e municipal (Façanha, 2003), embora não se tratasse de uso social do espaço, mas, sim, de atender a objetivos mercadológicos. Edificado a $7 \mathrm{Km}$ da área central de Teresina, o Parque Piauí configurava-se como área segregada e de forte concentração de pessoas de baixa renda (Teresina, 1969). Óbvio que esse processo de afastamento dos pobres para fora do adensamento urbano, observado à época, favoreceu a especulação imobiliária nas glebas intermediárias e se encontra na base de muitos processos de ocupações de terrenos urbanos ocorridas na cidade a partir, sobretudo, dos anos 1980 .

Todavia, como lembra Andrade (2016, p. 7), durante seus primeiros anos, o bairro Parque Piauí foi uma região desconectada do restante da cidade. 0 acesso ao Centro ainda era difícil pela falta de vias de acesso e o transporte público era escasso, o que o tornava um verdadeiro bairro dormitório. Para o autor, a "[...] imobilidade da população daquele bairro talvez tenha ressignificado seu sentido de comunidade" (Andrade, 2016, p. 7), e provavelmente potencializado a capacidade de organização e participação política, já que nesse bairro vamos encontrar práticas pioneiras na organização dos movimentos sociais e atores políticos que agitaram o final dos anos 1970 e toda a década de 1980. Afinal, no Parque Piauí, nasceram sementes de "libertação" nos tempos em que o povo que lá vivia iniciava um processo de resistência e de luta contra processos excludentes, do qual, pelo pioneirismo, vale registrar, iniciativas do conhecido Movimento contra a Carestia, que teve sua origem no Piauí naquelas paragens.

Como atesta Viana et al. (2019, p. 11), “[...] o apoio de setores da Igreja Católica foi fundamental no surgimento dos novos movimentos sociais no Estado", sendo o bairro Parque Piauí apontado em diversas pesquisas como "[...] um território especial de onde brotaram ideias, práticas e sujeitos novos, em face do trabalho pastoral de padres italianos que apoiaram ativamente os moradores do bairro na organização de lutas contra a carestia" que, sob o influxo da teologia da libertação, também foram fundamentais na 
organização de CEBs, de grupos pastorais, especialmente grupos de jovens e de grande significação no fortalecimento do novo sindicalismo, que dava os primeiros passos em solo piauiense naquela conjuntura. É neste contexto, e tendo o bairro Parque Piauí como cenário inicial, que nasceu também a tradição de manifestações do dia do Trabalhador no Estado. Silva (2000) afirma que em 1977 ocorreu a primeira manifestação pública de protesto ${ }^{4}$ nesta data, no bairro Parque Piauí, em Teresina, marcando essa data como uma oportunidade de denúncia e de reivindicação anual pelos trabalhadores.

Na atualidade, Teresina é uma cidade em expansão e espraiou-se bastante na direção Sul para além do bairro Parque Piauí e em todas as direções, apresentando uma população estimada em 864.845 pessoas (IBGE, 2019), consistindo em cidade-polo da Rede Integrada de Desenvolvimento da Grande Teresina, que envolve 15 municípios próximos, e, por conseguinte, demandando um sistema de transportes interligado que permite o deslocamento intraurbano satisfatório para seus habitantes, que, em grande parte, dependem do transporte coletivo. Essa demanda por transportes e mobilidade urbana é de longa data uma das questões que pautam os diferentes movimentos sociais na cidade, em especial os estudantis e populares.

Conforme o Plano Diretor de Transporte e Mobilidade Urbana de Teresina, de 2008, o aumento da população de Teresina teve por reflexo direto a demanda crescente por transporte coletivo. Considerando a evolução da demanda por transporte entre os anos de 1997 e 2006 e a média móvel de demanda mensal, deixaram de ser transportados cerca de 1,1 milhões de passageiros totais por mês e cerca de 1,5 milhões de passageiros equivalentes nos últimos dez anos (Teresina, 2008). Daí a necessidade, conforme o aludido plano, de remodelação da malha viária e instalação de um terminal de ônibus no Parque Piauí. Sem desconsiderar a necessidade do terminal, mas oferecendo resistência à construção do terminal na Praça do bairro Parque Piauí, foi formado o Movimento Ocupa Praça. Conforme destaca um dos entrevistados:

[...] na verdade, o Movimento, a gente deu início [...] quando os moradores da comunidade do Parque Piauí ficaram sabendo da construção de um terminal na Praça das ações comunitárias, que fica localizado bem na entrada do Parque Piauí e, aí, a partir desse momento, houve uma indignação dos moradores [...] nós fizemos uma passeata pelo Parque dizendo não à construção do terminal e aí, subimos todo o bairro e, na volta, a Praça já estava cheia de tapumes para início das obras e, aí, numa reunião muito rápida, entre as organizações que estavam presentes, como a REAPI [Rede Ambiental do Piauí], como as associações de outros bairros e os próprios moradores do Parque Piauí foi decidido a ocupação da Praça, [...] para que tentássemos um diálogo com a Prefeitura e não deixássemos que as obras realmente iniciassem [...] inclusive, uma das nossas ações diretas e emergenciais foi a retirada desses tapumes de metais que a construtora já havia colocado e, na volta desse ato que fizemos pelo Parque Piauí, decidimos ocupar [a praça] enquanto moradores e moradoras do Parque Piauí. (Engenheiro florestal, 2018).

É fato que a contestação a aspectos da implementação do Plano Diretor de Transporte de Teresina, no ano de 2015, foi catalizadora para o nascimento do Movimento, gerando suas demandas fundamentais. Ao representar uma ação direta contra o curso ditado por esse plano, o Movimento, em primeiro plano, marcou uma reação opositiva na esfera político-institucional contra o processo caracterizado por eles como espoliação urbana.

Mas essa não é a única explicação para o Ocupa Praça. Ao protagonismo dos moradores, enfatizado pelo informante na origem do Movimento, seguiu-se a constituição de uma rede formada por um mix de atores de representações distintas. Ou seja, foram sendo incorporados novos atores que reforçaram o campo discursivo popular da luta. Essa informação revela a importância das redes não só para o êxito do Movimento, como será mostrado, mas na própria constituição dele. Como explica Scherer-Warren (2003, p. 113), as redes de movimentos sociais pressupõem "[...] a identificação de sujeitos coletivos em torno de valores, objetivos ou projetos em comum, os quais definem os atores ou situações sistêmicas antagônicas que devem ser combatidas

\footnotetext{
${ }^{4}$ Durante a ditadura militar, na data de primeiro de maio, eram realizadas comemorações festivas, bem distintas, portanto, do caráter que passa a ter essa data quando do processo de retomada da democracia e da emergência de movimentos sociais combativos que, no final dos anos 1970, redesenham formas inovadoras de ação coletivas.
} 
e transformadas" e assim aproximam atores sociais diversificados, possibilitando o diálogo, permitindo, em última instância, que os movimentos sociais passem da defesa de um sujeito identitário único à defesa de um sujeito plural.

É nesse sentido que podemos afirmar que diferentes atores integraram o Ocupa Praça, seja na luta cotidiana do Movimento, seja como elos da rede de apoiadores que lhes deram sustentação ${ }^{5}$. Dentre os mais notórios apoiadores do movimento estão: a Rede Ambiental do Piauí (REAPI); o coletivo de arte Ocuparte; o Sindicato dos Servidores Públicos Municipais de Teresina (SINDISERM); além de estudantes da Universidade Federal do Piauí (UFPI) e da Universidade Estadual do Piauí (UESPI). Como ensina Scherer-Warren (1998, p. 22), à medida que se tecem relações sociais que constroem a identidade "[...] num processo dialógico de identificações éticas e culturais, intercâmbios, negociações, definição de campo de conflitos e de resistência aos adversários e aos mecanismos de exclusão sistêmica na globalização", pode-se traçar um mapa das conexões e elos presentes entre movimentos.

É válido sublinhar que um importante foco para a compreensão da análise de redes se inclina para a concepção tradicional de seus "nós", processados como elos interconectados por alguma forma de relacionamento e pautados sob um critério comum e específico (Diani, 2003).

Para Della Porta \& Diani (2006), a capacidade singular de arranjos como os supracitados se manifestarem, quando eles maximizam a adaptabilidade de implementação de novos atores na estrutura das redes, permitem a transposição da ação e a divisão dos efeitos do ato por todos os elos, proporcionando inovação e minimizando as falhas. 0 capital ativo do Movimento se constituiu nessa capacidade articulatória de congregar diversos atores em um só interesse, ou seja, a capacidade de o Ocupa Praça atrair apoio de diferentes setores sociais revelou-se uma das chaves explicativas de seu poder político. Com visões por vezes destoantes, porém complementares de mundo, esses atores potencializaram a ação do Movimento e permitiram um know-how de saberes que possibilitaram, dentro da arena política, cravar sua demanda. Conforme argumentam Della Porta \& Diani (2006), a aglutinação de esforços e habilidades formados por meio de alianças e parcerias estratégicas aparelha a organização a lidar com questões dramáticas e imprevisíveis, uma vez que esses atores contribuem com os repertórios em que são mais habilidosos.

Em outras palavras, o traço peculiar das redes se revela nessa diretiva sinérgica de buscar vínculos articulatórios e de promover interconexões de identidades num composto pluralista (Scherer-Warren, 2011) e em contínuo processo de formação da identidade, de definição de opositores e de construção de um projeto utópico emancipatório (Scherer-Warren, 2006, 2013). 0 importante, então, é analisar tais relações, é entender o que, de fato, permite esse encontro diverso e plural, é revelar o que os aproxima e o que permite "criar conectividade" (Diani \& Bison, 2010).

Em resposta ao Movimento, a Prefeitura Municipal de Teresina afirmou que os locais de construção do terminal "[...] foram escolhidos após uma ampla consulta popular, inclusive com a opinião dos moradores da região, que salientaram a necessidade de o terminal ser erguido num ponto acessível e estruturado" (Portal O Dia, 2015). No entanto, os entrevistados do Movimento pontuaram exatamente a ausência de diálogos iniciais, como atesta uma de suas integrantes (Advogada 1,2018), ao afirmar que: "[...] entre os lemas da Prefeitura Municipal, está a participação democrática que, a meu ver, não tem nada de democrática. Todas as vezes que há um canal de diálogo com a Prefeitura, é um canal de diálogo forçado pelo Movimento ou intermediado por uma instituição".

0 excerto acima contém forte crítica a um modelo avaliado como tecnocrático e a defesa de participação efetivamente democrática que deveria envolver algum "poder de decisão" da população. Espera-se a participação a partir dos ideais definidos na Constituição, mas ela não aconteceu. Em várias passagens, os militantes ressaltam a dialética forçada e o caráter antagônico e antidemocrático da situação. Autores como Della Porta \& Diani (2006) confirmam que os movimentos sociais não só

\footnotetext{
5 O Ocupa Praça se alimentou de influências e resistências preservacionistas em curso e exitosas em Teresina, a exemplo do movimento Viva Madalena, formado por estudantes da Universidade Federal do Piauí (UFPI), que, no ano de 2015, ocupou uma casa na região central de Teresina prestes a ser demolida, conseguindo preservá-la (Uchôa, 2015). A casa havia sido construída no ano de 1938, por isso era considerada de valor histórico arquitetônico para a cidade (Pereira, 2015).
} 
espelham a crítica à política clássica, mas invocam um elemento antigo e esquecido na teoria democrática: o teor coletivo das decisões.

Ao expor os limites impostos no plano institucional, os militantes traçaram arenas discursivas e de debate público de suas demandas, ao manterem-se de forma ativa na ocupação da praça por seguidos meses, buscando evitar a remoção das árvores. Na direção de novos caminhos, as estratégias moveram-se também no campo institucional ao ocuparem outras esferas políticas, num sentido que integrava "[...] ora espaços institucionais, ora não institucionais", assim como observado em outros movimentos sociais (cf. Carlos, 2017, p. 340). Conforme os entrevistados, atuando no confronto e na ação direta em defesa da Praça e de suas árvores, o Movimento também agia no apelo a canais judiciais, como o Ministério Público, a OAB e as audiências públicas.

Uníssono entre os entrevistados é o reconhecimento da elaboração de argumentos viáveis do ponto de vista legal e social para sensibilização em defesa de suas demandas. Avalia uma entrevistada:

o argumento deles, o que abre um precedente terrível, por que se as custas de economizar dinheiro, fazer contenção orçamentária, quando a Prefeitura quiser construir uma coisa, sair construindo nas Praças de Teresina, daqui a pouco nós não vamos ter nenhuma Praça, porque, enfim, terreno é caro em Teresina, imóvel não é tão barato, mas a gente conseguia mostrar essas contradições e [...], essas contradições deixavam os técnicos da Prefeitura muito chateados [...] eu acho que nesse sentido aí, a gente era muito eficaz, a gente estudava, o pessoal da arquitetura, os estudantes da arquitetura estudavam os planos que tão lá, disponível na internet, e mostrava as contradições e eram uma boa estratégia, essa de expor as contradições dos discursos deles (Advogada 1,2018).

A entrevistada questiona o custo social e ambiental do "desenvolvimento" pretendido pela prefeitura e expõe a crítica a esse modelo, uma preocupação não só específica à situação do bairro, mas conexa à condução da política aplicada no contexto geral da cidade. Ao evocar argumentos extensivos a diversos grupos, o movimento construiu e obteve poder aglutinador. Nesse sentido, o Movimento conseguiu mobilizar de certa forma a população teresinense, sensibilizando a sociedade quanto aos conteúdos mais gerais das questões e das políticas urbanas postos pela luta local. Essa observação foi explicitada por um assessor técnico da Prefeitura:

O impacto do Movimento em si - apesar da gente considerar que o Movimento teve muita inspiração político eleitoreira, muita gente apareceu que não tinha nada a ver com a história, fez barulho, fez parte do processo -, o impacto, ao meu ver, se restringiu a esse aspecto: contribuiu para que se notasse uma posição técnica melhor. [...] E também, [...] teve o aspecto positivo indireto: levantou-se mais interesse também pela própria discussão do problema, da integração, do projeto (2018).

Com efeito, o Ocupa Praça conseguiu dar visibilidade ao fato social local e o converter em uma demanda extensiva a toda a sociedade teresinense. Mais que isso, para lograr o apoio social, a campanha do Movimento entrelaçou conteúdos jurídicos, políticos e sociais num projeto que se movimenta para além de uma circunscrição institucional, reverberando para outros polos de discussão social e política. A visibilidade da questão trouxe esse ganho imaterial que reside em atrair a atenção para a gestão da cidade, ou seja, de influenciar o corpo social, ainda que de forma difusa (Della Porta \& Diani, 2006).

Identificamos que o legado maior se reproduz na forma como o Movimento atuou na comunidade, envolvendo vários nós ou elos de uma rede de ativistas e movimentos como um ganho social de peso para a sociedade civil. Assim, o Ocupa Praça não somente os unificou a partir de uma causa específica, mas potencializou as identificações em processos de lutas possíveis a partir de então.

Nesse sentido, seu êxito foi mais do que a preservação da Praça. O Movimento conseguiu pautar temáticas distintas: o planejamento urbano, o direito à cidade, o patrimônio, o meio ambiente, o lazer e a participação política, sensibilizando a população. Ademais, estabeleceram-se redes de atores políticos e sociais, que ajudam a explicar a gênese, atuação e sucesso do Movimento, além de possíveis desdobramentos em novas demandas políticas e sociais.

Melucci (1989), ao discorrer sobre a relevância dos movimentos sociais contemporâneos circunscritos a seus efeitos práticos e simbólicos, expõe uma lógica não refratária a um resultado negativo 
ou positivo de "fracasso ou êxito". Mas afirma que a proposta em si, com valor para os movimentos consiste em provocar a ruptura de padrões de dominação vigentes. 0 autor salienta que, do ponto de vista político, os movimentos produzem modernização, estimulam a inovação e impulsionam a reforma. Portanto, desse ponto de vista, seu resultado pode ser medido, ainda que seja apenas uma parte nem sempre importante da ação coletiva (Melucci, 1989).

No entanto, devemos assumir uma visão ponderada do resultado desse Movimento, afinal, não se constatou uma transformação sistêmica no campo institucional. Contudo, voltado para o terreno social, a maior competência do Ocupa Praça se reproduz na ressignificação da sociedade na política ao ser instigada a abrir-se ao diálogo com atores civis que, pautando seus interesses, tencionaram o processo decisório e o obrigaram a alterar seu rumo.

\section{Conclusões}

O Movimento Ocupa Praça foi um Movimento direcionado à defesa de uma Praça no bairro Parque Piauí em Teresina, implicando a questão social, ambiental e política. Mediante um processo de aproximação solidária construiu estratégias e definiu seus propósitos e objetivos no confronto com a direção da política pública local sob o comando da Prefeitura de Teresina, ousando pôr em xeque também o conteúdo da participação dos moradores nas políticas locais. Ao dar publicidade ao custo social e à questão ambiental, caso a Praça (e suas árvores) fosse destruída, o Movimento atraiu adesão para suas narrativas junto a outros movimentos, instituições e a sociedade em geral.

Como resultados da análise que processamos sobre o Ocupa Praça, destacamos a presença acentuada de "nós" de uma rede movimentalista que ampliou o poder de interlocução do Movimento na arena pública, por meio de um portfólio substanciado de práticas, experiências, saberes e canais de articulação política que gerou impacto e influência sobre a política de mobilidade urbana e a qualificação da decisão pública, com conquista substantiva para os atores sociais envolvidos nesta luta, processo esse que, após nove meses de intensas atividades, redundou na manutenção da Praça (com suas árvores preservadas). Assim, o Ocupa Praça, após um longo processo de mediação e de diálogo político, conseguiu lograr êxito, como reflexo de uma articulação estratégica coordenada e organizada.

E, por fim, cumpre-nos ressaltar que a pesquisa desenvolvida acerca da Ocupa Praça permitiu demonstrar a potencialidade da teoria das redes na análise dos movimentos sociais em suas relações com os canais institucionais de disputa política. Afinal, os movimentos ganham relevância política quando combinam múltiplas conexões e instâncias para vocalizar suas demandas, podendo, os distintos elos da rede, dadas suas potencialidades específicas, contribuírem cada um a seu modo para firmar seus interesses na arena política de forma exitosa.

Como sugestão prática e teórica, ressaltamos a importância da construção e análise de redes de atores que, por vezes, são tratados de forma singular, tais como movimentos sociais, associações profissionais, partidos políticos e instituições estatais.

\section{Referências}

Abers, R., \& Von Bülow, M. (2011). Movimentos sociais na teoria e na prática: como estudar o ativismo através da fronteira entre Estado e sociedade? Sociologias, 13(28), 52-84. http://dx.doi.org/10.1590/S151745222011000300004.

Abers, R., Serafim, L., \& Tatagiba, L. (2014). Repertórios de interação Estado-sociedade em um Estado heterogêneo: a experiência na Era Lula. Dados, 57(2), 325-357. http://dx.doi.org/10.1590/0011-5258201411.

Alonso, A. (2009). As teorias dos movimentos sociais: um balanço do debate. Lua Nova: Revista de Cultura e Política, 76(76), 49-86. http://dx.doi.org/10.1590/S0102-64452009000100003. 
Andrade, L. R. A. (2016). Gênesis, direitos e revolução: Parque Piauí, 1968-2016. In Anais da I Semana Acadêmica de Ciência Política da UFPI. Teresina: ADUFPI. Recuperado em 24 de fevereiro de 2018, de https://drive.google.com/file/d/0B2P4fUu4q_52dFlONVVaUDNSY2M/view

Avritzer, L., \& Costa, S. (2004). Teoria crítica, democracia e esfera pública: concepções e usos na América Latina. Dados, 47(4), 703-728. http://dx.doi.org/10.1590/S0011-52582004000400003.

Brasil. (1988, 5 de outubro). Constituição da República Federativa do Brasil de 1988. Brasília: Diário Oficial da União. Recuperado em 10 de abril de 2018, de

http://www.planalto.gov.br/ccivil_03/constituicao/ConstituicaoCompilado.htm

Cardoso, R. C. L. (1987). Movimentos sociais na América Latina. Revista Brasileira de Ciências Sociais, 1(3), 27-37. Recuperado em 24 de fevereiro de 2020, de http://www.anpocs.com/images/stories/RBCS/03/rbcs03_02.pdf

Carlos, E. (2017). Cooperação e conflito na relação movimentos sociais e estado. Política \& Sociedade, 16(35), 321350. http://dx.doi.org/10.5007/2175-7984.2017v16n35p321.

Castells, M. (2001). La Galaxia Internet: reflexiones sobre internet, empresa y sociedad. Barcelona: Areté. http://dx.doi.org/10.1007/978-3-322-89613-1.

Castells, M. (2005). A sociedade em rede (8. ed., Vol. 1). São Paulo: Paz e Terra.

Castells, M. (2013). Redes de indignação e esperança: movimentos sociais na era da internet. Rio de Janeiro: Zahar.

Cayres, D. (2017). Ativismo institucional e interações Estado-movimentos sociais. BIB: Revista Brasileira de Informação Bibliográfica em Ciências Sociais, (82), 81-104. Recuperado em 24 de fevereiro de 2020, de https://www.anpocs.com/index.php/bib-pt/bib-82/10586-ativismo-institucional-e-interacoes-estadomovimentos-sociais/file

Della Porta, D., \& Diani, M. (2006). Social Movements: an introduction (2. ed.). Oxford: Blackwell Publishing.

Diani, M. (1992). The concept of social movement. The Sociological Review, 40(1), 1-25.

http://dx.doi.org/10.1111/j.1467-954X.1992.tb02943.x.

Diani, M. (2003). Introduction: social movements, contentious actions, and social networks: 'from metaphor to substance'? In M. Diani, \& D. McAdam (Eds.), Social movements and networks: relational approaches to collective action: comparative politics. New York: Oxford University Press.

Diani, M., \& Bison, I. (2010). Organizações, coalizões e movimentos. Revista Brasileira de Ciência Política, (3), 220249. Recuperado em 24 de fevereiro de 2020, de https://periodicos.unb.br/index.php/rbcp/article/view/1681/1478

Doimo, A. M. (1995). A vez e a voz do popular: movimentos sociais e participação política no Brasil pós-70. Rio de Janeiro: Relume-Dumará.

Dowbor, M. (2012). A arte da institucionalização: estratégias de mobilização dos sanitaristas (1974-2006) (Tese de doutorado). Faculdade de Filosofia, Letras e Ciências Humanas, Universidade de São Paulo, São Paulo.

Façanha, A. C. (2003). A evolução urbana de Teresina: passado, presente e.... Carta CEPRO, 22(1), 59-69.

Recuperado em 24 de fevereiro de 2020, de

https://www.google.com/url?sa=t\&rct=j\&q=\&esrc=s\&source=web\&cd=1\&ved=2ahUKEwj_tL7ovurnAhWmHbkG HeLgBz0QFjAAegQIAxAB\&url=https\%3A\%2F\%2Fsigaa.ufpi.br\%2Fsigaa\%2FverProducao\%3FidProducao\%3D87 7156\%26key\%3D9fcac448d38db120e1f951238806e74d\&usg=AOvVaw3dn-iC32ozfJmOUzSAL4y0

Gohn, M. G. (2000). 500 anos de lutas sociais no Brasil: movimentos sociais, ONGs e terceiro setor. Mediações, 5(1), 11-40. http://dx.doi.org/10.5433/2176-6665.2000v5n1p11.

Gohn, M. G. (2010). Novas teorias dos movimentos sociais (3. ed.). São Paulo: Edições Loyola.

Gohn, M. G. (2011). Conselhos gestores e participação sociopolítica (4. ed., Vol. 32). São Paulo: Cortez.

Instituto Brasileiro de Geografia e Estatística - IBGE. (2019). Cidades: Teresina. Recuperado em 24 de fevereiro de 2020, de https://cidades.ibge.gov.br/brasil/pi/teresina/panorama 
Labra, M., \& Figueiredo, J. (2002). Associativismo, participação e cultura cívica: o potencial dos Conselhos de Saúde. Ciência \& Saúde Coletiva, 7(3), 537-547. http://dx.doi.org/10.1590/S1413-81232002000300011.

Lavalle, A. G. (2003). Sem pena nem gloria: o debate da sociedade civil nos anos 1990. Novos Estudos CEBRAP, (66), 91-110. Recuperado em 23 de fevereiro de 2020, de https://www.researchgate.net/publication/258220356_Sem_pena_nem_gloria__O_debate_da_sociedade_civil_nos_anos_1990

Lavalle, A. G., \& Szwako, J. (2015). Sociedade civil, Estado e autonomia: argumentos, contra-argumentos e avanços no debate. Opinião Pública, 21(1), 157-187. http://dx.doi.org/10.1590/1807-0191211157.

Lavalle, A. G., Carlos, E., Dowbor, M., \& Szwako, J. (2019). Movimentos sociais, institucionalização e domínios de agência. In A. G. Lavalle, E. Carlos, M. Dowbor, \& J. Szwako (Eds.), Movimentos sociais e institucionalização: políticas sociais, raça e gênero no Brasil pós-transição. Rio de Janeiro: EdUERJ.

Matos, M., \& Paradis, C. G. (2014). Desafios à despatriarcalização do Estado brasileiro. Cadernos Pagu, 43(43), 57118. http://dx.doi.org/10.1590/0104-8333201400430057.

Melucci, A. (1989). Um objetivo para os movimentos sociais? Lua Nova: Revista de Cultura e Política, 17(17), 49-66. http://dx.doi.org/10.1590/S0102-64451989000200004.

Pereira, R. (2015, 9 de julho). Viva Madalena: casarão permanece ocupado e jovens terão que depor. Cidade Verde. Recuperado em 19 de janeiro de 2020, de https://cidadeverde.com/noticias/197160/viva-madalena-casaraopermanece-ocupado-e-jovens-terao-que-depor

Perez, O. C., \& Santos, G. G. C. (2019). A produção acadêmica sobre participação social no Brasil: trajetória e agendas de pesquisa. BIB: Revista Brasileira de Informação Bibliográfica em Ciências Sociais, (90), 1-22. http://dx.doi.org/10.17666/bib9005/2019.

Pires, R. R. C., \& Vaz, A. C. N. (2014). Para além da participação: interfaces socioestatais no governo federal. Lua Nova: Revista de Cultura e Política, 93(93), 61-91. http://dx.doi.org/10.1590/S0102-64452014000300004.

Portal O Dia. (2015). Moradores da Zona Sul ocupam Praça para evitar retirada de arvores. Teresina: Portal 0 Dia. Recuperado em 1 de fevereiro de 2020, de https://www.portalodia.com/noticias/piaui/moradores-da-zona-sulocupam-praca-para-evitar-retirada-de-arvores-249191.html

Ribeiro, A. C. T. (2009). Cartografia da ação social, região latino-americana e novo desenvolvimento urbano. In H. Poggiese, \& T. T. C. Egler (Eds.), Outro desarrollo urbano: ciudad incluyente, justicia social y gestión democratica (pp. 147-156). Buenos Aires: CLACSO.

Sader, E. (1988). Quando novos personagens entraram em cena: experiências, falas e lutas dos trabalhadores da Grande São Paulo: 1970-80. Rio de Janeiro: Paz e Terra.

Santos, O. A., Jr., Ribeiro, L. C. Q., \& Azevedo, S. (2004). Governança democrática e poder local: a experiência dos Conselhos Municipais no Brasil. Rio de Janeiro: Revan/Fase.

Scherer-Warren, I. (1998). Movimentos em Cena: ... e as teorias por onde andam? Revista Brasileira de Educação, (9), 16-29. Recuperado em 24 de fevereiro de 2020, de http://anped.tempsite.ws/novo_portal/rbe/rbedigital/RBDE09/RBDE09_04_ILSE_SCHERER-WARREN.pdf

Scherer-Warren, I. (2003). Sujeitos e movimentos conectando-se através de Redes. Política \& Trabalho, (19), 2937. Recuperado em 24 de fevereiro de 2020 , de https://periodicos.ufpb.br/ojs/index.php/politicaetrabalho/article/view/6501/4066

Scherer-Warren, I. (2005a). Redes de movimentos sociais num mundo multicultural. Revista Katálysis, 8(1), 24-31.

Scherer-Warren, I. (2005b). Redes sociales y de movimientos en la sociedad de la información. Revista Nueva Sociedad, (196), 77-92. Recuperado em 24 de fevereiro de 2020, de https://nuso.org/articulo/redes-sociales-y-demovimientos-en-la-sociedad-de-la-informacion/

Scherer-Warren, I. (2006). Das mobilizações às redes de movimentos sociais. Sociedade e Estado, 21(1), 109-130. http://dx.doi.org/10.1590/S0102-69922006000100007. 
Scherer-Warren, I. (2007). Fóruns e redes da sociedade civil: percepções sobre exclusão social e cidadania. Revista Política \& Sociedade, 6(11), 19-40. http://dx.doi.org/10.5007/\%25x.

Scherer-Warren, I. (2008). Movimentos sociais no Brasil contemporâneo. História: Debates e Tendências, 7(1), 921. Recuperado em 24 de fevereiro de 2020, de http://seer.upf.br/index.php/rhdt/article/view/2947/1994

Scherer-Warren, I. (2011). Redes de movimentos sociais (5. ed.). São Paulo: Loyola.

Scherer-Warren, I. (2013). Redes e movimentos sociais projetando o futuro. Revista Brasileira de Sociologia, 1(1), 187-217. http://dx.doi.org/10.20336/rbs.29.

Silva, M. R. F. (2000). Comerciários e Bancários: experiências coletivas no Novo Sindicalismo (Tese de doutorado). Faculdade de Ciências Sociais, Pontifícia Universidade Católica de São Paulo, São Paulo.

Tarrow, S. (2009). O poder em movimento: movimentos sociais e confronto político (1. ed.). Petrópolis: Vozes.

Tatagiba, L. (2002). Os Conselhos Gestores e a democratização das políticas públicas no Brasil. In E. Dagnino (Ed.), Sociedade civil e espaços públicos no Brasil (pp. 47-104). São Paulo: Paz e Terra.

Teresina. (1969). Plano de desenvolvimento local integrado de Teresina. COPLAN S.A. Construções e Planejamento.

Teresina. Prefeitura. (2008). Plano Diretor de Transporte e Mobilidade Urbana de Teresina. Recuperado em 20 de julho de 2020, de https://semplan.teresina.pi.gov.br/plano-diretor-de-transporte-e-mobilidade-urbana-deteresina/

Teresina. Prefeitura. (2015). PMT apresenta propostas de compensação ambiental para o Parque Piauí. Recuperado em 25 de janeiro de 2020, de https://semplan.teresina.pi.gov.br/2015/11/06/pmt-apresenta-propostas-decompensacao-ambiental-para-o-parque-piaui/

Tilly, C. (2010). Os movimentos sociais como política. Revista Brasileira de Ciência Política, 3, 133-160. Recuperado em 20 de julho de 2017, de https://periodicos.unb.br/index.php/rbcp/article/view/1677/1475

Toni, F. (2001). Novos rumos e possibilidades para o estudo dos movimentos sociais. BIB: Revista Brasileira de informação Bibliográfica em Ciências Sociais, (52), 79-104. Recuperado em 24 de fevereiro de 2020, de https://anpocs.com/index.php/bib-pt/bib-52/526-novos-rumos-e-possibilidades-para-os-estudos-dosmovimentos-sociais/file

Touraine, A. (1989). Os novos conflitos sociais para evitar mal-entendidos. Lua Nova: Revista de Cultura e Política, 17(17), 5-18. http://dx.doi.org/10.1590/S0102-64451989000200002.

Uchôa, G. (2015, 19 de julho). Movimento \#vivamadalena alerta para preservação de prédios históricos. Teresina: Portal O Dia. Recuperado em 22 de janeiro de 2020, de

https://www.portalodia.com/esporte/esporte/movimento-vivamadalena-alerta-para-preservacao-de-predioshistoricos-241679.html

Viana, M. R., Oliveira, F. M., \& Medeiros, L. B. (2019). Apresentação. In M. R. Viana, F. M. Oliveira, \& L. B. Medeiros (Eds.), Sociedade civil e movimentos sociais no Piauí (pp. 7-17). Teresina: EDUFPI.

\section{Editor: Rodrigo Firmino}

Recebido: Jul. 21, 2019

Aprovado: Jun. 01, 2020 